\title{
Defective glucose and lipid metabolism in human immunodeficiency virus-infected patients with lipodystrophy involve liver, muscle tissue and pancreatic $\beta$-cells
}

Steen B Haugaard ${ }^{1,2,3}$, Ove Andersen ${ }^{1,3}$, Flemming Dela ${ }^{5}$, Jens Juul Holst ${ }^{6}$, Heidi Storgaard ${ }^{7}$, Mogens Fenger ${ }^{4}$ Johan Iversen $^{1}$ and Sten Madsbad ${ }^{2}$

${ }^{1}$ Department of Infectious Diseases, ${ }^{2}$ Department of Internal Medicine and Endocrinology, ${ }^{3}$ Clinical Research Unit and ${ }^{4}$ Department of Clinical Biochemistry, Hvidovre University Hospital, Copenhagen, Denmark, ${ }^{5}$ Copenhagen Muscle Research Centre/Department of Medical Physiology and ${ }^{6}$ Department of Medical Physiology, The Panum Institute, University of Copenhagen, Copenhagen, Denmark and ${ }^{7}$ Steno Diabetes Centre, Gentofte, University of Copenhagen, Copenhagen, Denmark

(Correspondence should be addressed to S B Haugaard, Clinical Research Unit 136, Hvidovre University Hospital, DK 2650 Hvidovre, Copenhagen, Denmark; Email:sbhau@dadlnet.dk)

\begin{abstract}
Objectives: Lipodystrophy and insulin resistance are prevalent among human immunodeficiency virus (HIV)-infected patients on combined antiretroviral therapy (HAART). Aiming to provide a detailed description of the metabolic adverse effects of HIV-lipodystrophy, we investigated several aspects of glucose metabolism, lipid metabolism and $\beta$-cell function in lipodystrophic HIV-infected patients. Methods: $\left[3-{ }^{3} \mathrm{H}\right]$ glucose was applied during euglycaemic hyperinsulinaemic clamps in association with indirect calorimetry in 43 normoglycaemic HIV-infected patients (18 lipodystrophic patients on HAART (LIPO), 18 patients without lipodystrophy on HAART (NONLIPO) and seven patients who were naïve to antiretroviral therapy (NAÏVE) respectively). $\beta$-cell function was evaluated by an intravenous glucose tolerance test.

Results: Compared with NONLIPO and NAÏVE separately, LIPO displayed markedly reduced ratio of limb to trunk fat (RLF; $>34 \%, P<0.001$ ), hepatic insulin sensitivity $(>40 \%, P<0.03$ ), incremental glucose disposal $(>50 \%, P<0.001)$ and incremental exogenous glucose storage $(>50 \%$, $P<0.05)$. Furthermore, LIPO displayed reduced incremental glucose oxidation $(P<0.01)$, increased clamp free fatty acids $(P<0.05)$ and attenuated insulin-mediated suppression of lipid oxidation $(P<0.05)$ compared with NONLIPO. In combined study groups, RLF correlated with hepatic insulin sensitivity $(r=0.69)$, incremental glucose disposal $(r=0.71)$ and incremental exogenous glucose storage $(r=0.40)$, all $P<0.01$. Disposition index (i.e. first-phase insulin response to intravenous glucose multiplied by incremental glucose disposal) was reduced by $46 \%(P=0.05)$ in LIPO compared with the combined groups of NONLIPO and NAÏVE, indicating an impaired adaptation of $\beta$-cell function to insulin resistance in LIPO.

Conclusion: Our data suggest that normoglycaemic lipodystrophic HIV-infected patients display impaired glucose and lipid metabolism in multiple pathways involving liver, muscle tissue and $\beta$-cell function.
\end{abstract}

European Journal of Endocrinology 152 103-112

\section{Introduction}

The prevalence rate of fat redistribution in human immunodeficiency virus (HIV)-infected patients receiving highly active antiretroviral therapy (HAART) for more than 1 year is approximately $40 \%$ (1). The major phenotypic trait of HIV-associated lipodystrophy syndrome (HALS) is loss of extremity fat including facial and gluteal regions and fat gain in the trunk region (2). Metabolically, the syndrome is characterized by insulin resistance $(3,4)$, impaired glucose tolerance $(5,6)$ and hepatic insulin resistance (7). Also, fat metabolism is disturbed with reports on increased lipolysis (8), increased fat deposition in the liver (9) and muscle tissue $(10,11)$, increased expression of tumour necrosis factor- $\alpha$ in fat tissue and decreased plasma levels of adiponectin (12). The subcutaneous fat atrophy in the leg region has been positively related to a high level of fasting insulin and fasting C-peptide, indicating a relationship between insulin resistance and fat distribution $(5,13)$.

We recently reported that HIV-infected patients who had lipodystrophy compared with HIV-infected patients without fat redistribution, exhibited deterioration in insulin sensitivity (14). In the present study, we have investigated in more detail several aspects of the glucose 
and lipid metabolism in this cohort of normoglycaemic HIV-infected patients on HAART with and without fat redistribution using data from a hyperinsulinaemic euglycaemic clamp combined with tritiated glucose infusions and indirect calorimetry. In this study, we also included normoglycaemic HIV-infected patients who had not been treated with antiretroviral drugs. The associations between fat distribution and measures of hepatic insulin sensitivity, glucose and fat metabolism were examined, aiming to provide new insight into substrate metabolism in HIV-lipodystrophy. The $\beta$-cell function was evaluated comparing the firstphase insulin secretion response following an intravenous glucose bolus with the incremental peripheral glucose disposal to examine whether the insulin response in HIV-lipodystrophy might compensate for the degree of insulin resistance in the patients.

\section{Patients and methods}

\section{Subjects}

Forty-three HIV-1 positive men were recruited from the outpatient clinic of infectious diseases at Hvidovre Hospital, University of Copenhagen, Denmark. All HIV-infected patients had to have plasma glucose $<7.0 \mathrm{mmol} / \mathrm{l}$ following a $12-\mathrm{h}$ fast, and must be older than 25 years of age. Each subject filled in a standardized questionnaire including nine criteria of lipodystrophy (loss of fat in face, arms, legs, buttocks, gain of abdominal and trunk fat, more exposed veins, fat pads in the neck region and lipomas). A trained physician carried out a complete physical examination (examination for lipoatrophy in face, extremities, buttocks, abdominal obesity, buffalo hump and lipomas). The patient had to report at least one of the criteria of lipodystrophy and present at least one of the six signs of lipodystrophy in order to be categorized as exhibiting HALS. Lipohypertrophy as the only reported symptom or sign was not accepted for inclusion as a lipodystrophic patient. The questionnaire and physical examination had to be negative for signs of lipodystrophy for a patient to be included as a control subject. According to these definitions, 18 HIV-infected patients had HALS and were under medication with HAART (i.e. LIPO), 18 HIV-infected patients on HAART did not exhibit redistribution of fat (i.e. NONLIPO) and seven HIVinfected patients did not display redistribution of fat and had never received antiretroviral drugs (i.e. NAÏVE). Notably, in the LIPO group of 18 patients, 17 patients complained and were found to display a combination of peripheral fat loss and central fat accumulation, whereas one single patient with multiple lipomas was accepted as a case patient (i.e. LIPO). Exclusion criteria were chronic disease other than HIV infection, an AIDS-related episode or acute infection within the latest 3 months, weight loss or gain above $4 \mathrm{~kg}$ within 6 months, treatment with lipid lowering agents or antidiabetic drugs. Except for HAART, none of the subjects received medication known to affect glucose metabolism. All but two participants were of Caucasian ethnicity and only two of the participants had a family history of diabetes mellitus, both of them being in the NONLIPO group. Subjects gave their written informed consent and the protocol was approved by the Ethical Committee in Copenhagen, Denmark, and performed in accordance with the Helsinki Declaration II.

\section{Experimental protocol}

Instructions were given to abstain from strenuous exercise for at least 3 days before the metabolic assessments. The HIV-infected patients reported to our laboratory at $0800 \mathrm{~h}$ following a 12-h overnight fast, including a 16-h withdrawal of HAART. At $0830 \mathrm{~h}$ two intravenous cannulas were inserted, one in a dorsal hand vein and the other in a contralateral antecubital vein. The hand vein was used for blood sampling, whereas the antecubital vein was used for infusion. A primed continuous infusion of $3-{ }^{3} \mathrm{H}$-tritiated glucose (bolus: $2.05 \mu \mathrm{Ci} / \mathrm{mmol}$ per 1 fasting plasma (p-) glucose; continuous: $0.11 \mu \mathrm{Ci} / \mathrm{min}$; New England Nuclear, Boston, MA, USA) was initiated at $0900 \mathrm{~h}$ at the start of the 150-min basal period (0-150 min) and continued throughout the basal period, a 30-min intravenous glucose tolerance test (IVGTT; $150-180 \mathrm{~min}$ ) and a 120min hyperinsulinaemic euglucemic clamp (180$300 \mathrm{~min}$ ) respectively. Two steady-state periods were predefined, i.e. at 90-120 min (basal) and 270300 min (clamp). During both steady-state periods indirect calorimetry was performed using a computerized canopy gas analyzer system (Deltatrac II Metabolic Monitor; Datex, Helsinki, Finland) to estimate non-protein glucose and lipid oxidation rates as previously described (15). The IVGTT was initiated with a 1-min bolus glucose infusion $(0.3 \mathrm{~g} / \mathrm{kg}$ body weight $(\mathrm{BW}))$. Blood samples for glucose and insulin were drawn relative to the start of the glucose bolus at $-4,-2,0,2,4$, $6,8,10,15,20$ and $30 \mathrm{~min}$. Thereafter, insulin (Actrapid; Novo Nordisk A/S, Bagsvaerd, Denmark) infusion rate of $100 \mathrm{mU} / \mathrm{m}^{2}$ per min with a stepwise decline in infusion rate every third minute by $20 \mathrm{mU} / \mathrm{m}^{2}$ per min until an insulin infusion rate of $40 \mathrm{mU} / \mathrm{m}^{2}$ per min was reached after $9 \mathrm{~min}$. For the remaining $111 \mathrm{~min}$ of the clamp, insulin infusion rate was fixed at $40 \mathrm{mU} / \mathrm{m}^{2}$ per min. Plasma glucose concentration was kept at $\approx 5 \mathrm{mmol} / \mathrm{l}$ by adjusting the infusion rate of glucose $(180 \mathrm{~g} / \mathrm{l})$, which was enriched with tritiated glucose $(110 \mu \mathrm{Ci} / \mathrm{l})$. During the clamp, glucose levels were determined every $5 \mathrm{~min}$, and blood samples for assessing plasma insulin levels were taken every 10 min. Blood samples for assessing plasma glycerol, alanine, lactate, glucagons, total cholesterol, high density lipoprotein (HDL) cholesterol and triglyceride were taken during the basal fasting period at 90 and $120 \mathrm{~min}$, and during the clamp at 270 and $300 \mathrm{~min}$, 
whereas blood samples for free fatty acids (FFAs) were taken more frequently (see Fig. 1). Body composition was evaluated by dual energy X-ray absorptiometry (DEXA) (Norland, WI, USA). To estimate the amount of fat in the trunk (chest, abdomen and pelvis) and in the extremities a whole-body scan was performed. The proximal limitation of the leg region was placed through the hip joints at an angle of approximately 45 degrees. The DEXA scans were done in random order, and the operator was unaware of the assignment of the patients to study groups.

\section{Analytical procedures}

The whole blood glucose levels were determined pairwise on two calibrated HemoCue B-Glucose Analyzers (HemaCue AB, Angelholm, Sweden) with an intra-analyzer coefficient of variation (C.V.) of 3.5\% and an interanalyzer C.V. of $3.3 \%$. Plasma glucose was calculated using the equations of Fogh-Andersen \& D'Orazio (16) filling in data on whole blood glucose (the mean of the pair of measurements) and blood haematocrit. Plasma insulin blood samples were centrifuged immediately at $4{ }^{\circ} \mathrm{C}$ and stored at $-80{ }^{\circ} \mathrm{C}$ for later analysis. Plasma insulin concentration was determined by 1235 AutoDELPHIA automatic immunoassay system (Wallac Oy, Turku, Finland). The insulin assay had a detection limit of approximately $3 \mathrm{pM}$. Cross-reactivity with intact proinsulin was $0.1 \%, 0.4 \%$ with $32-33$ split proinsulin and $66 \%$ with $64-65$ split proinsulin, intra-assay C.V. of $4.5 \%$ and interassay C.V. of $7 \%$. Plasma FFAs were determined using an enzymatic colorimetric method (Wako C test kit; Wako Chemicals $\mathrm{GmbH}$, Neuss, Germany) with an interassay C.V. of $5 \%$. Total serum cholesterol, HDL cholesterol and serum triglycerides were determined by reflection photometry (Ortho-Clinical Diagnostics kit, Raritan, NJ, USA) with interassay C.V. values of 2,8 and $2.5 \%$ respectively. CD4 count determination (flow cytometry; Becton-Dickinson FACscan, Frankling Lakes, NJ, USA; interassay C.V. of $7 \%$ ) and viral load determination (Roche Amplicor and Roche amplicer ultrasensitive assay with a detection limit of 20 copies/ml plasma; Roche, Basel, Switzerland) met the requirements of interlaboratory quality control. The glucagon assay (17) is directed against the $\mathrm{COOH}$-terminus of the glucagon molecule and therefore measures glucagon of mainly pancreatic origin. Detection limit and intraassay C.V. of the assay used was $1 \mathrm{pmol} / \mathrm{l}$ and $<6 \%$. Given that the glucagon concentration was lower than the detection limit, a value of $0.5 \mathrm{pmol} / \mathrm{l}$ was noted. Concentrations of alanine and glycerol were measured by a spectrophotometric method (Hitachi 912 automated analyzer; Roche, Hvidovre, Denmark). Plasma lactate was measured by an enzymatic kit (Roche Diagnostics $\mathrm{GmbH}$, Mannheim, Germany) on an automatic analyzer (Hitachi 912). Tritiated glucose and water was measured as previously described (18).

\section{Calculations}

Ratio of limb fat to trunk fat (RLF) was calculated as the extremity fat mass (total fat in arms and legs) expressed as percentage of fat mass in the trunk region. RLF was
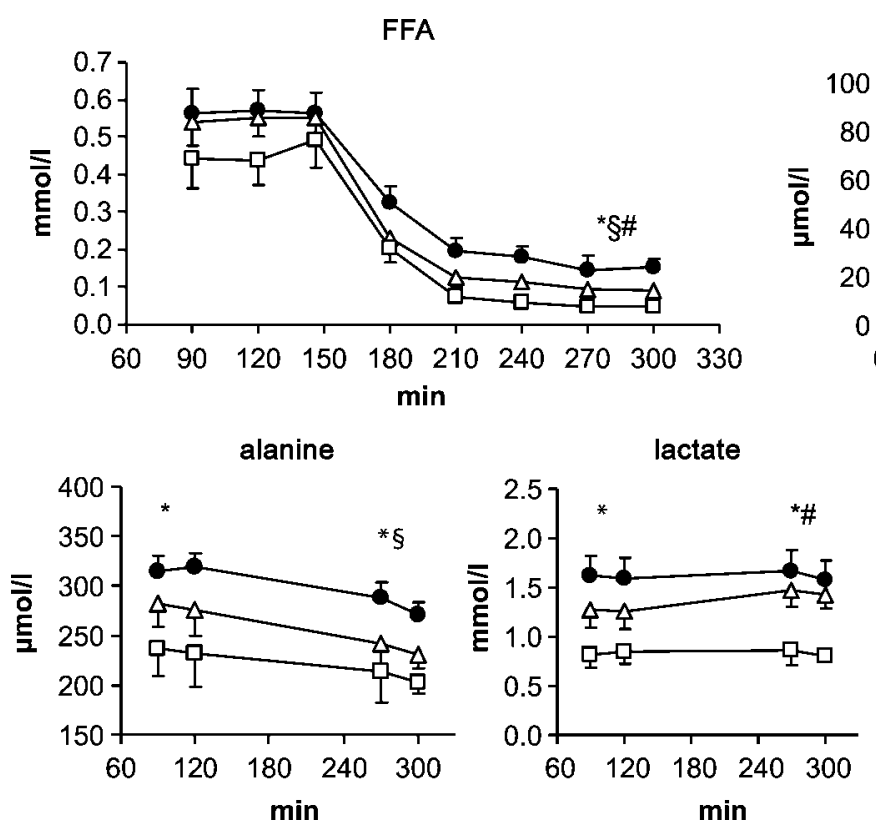

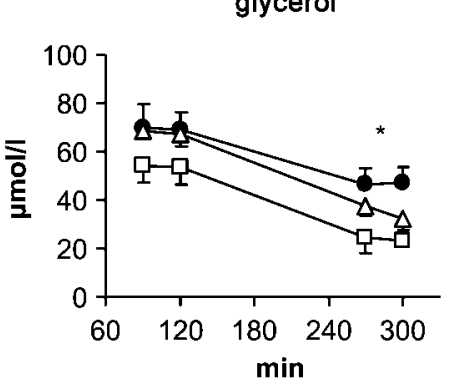

glucagon

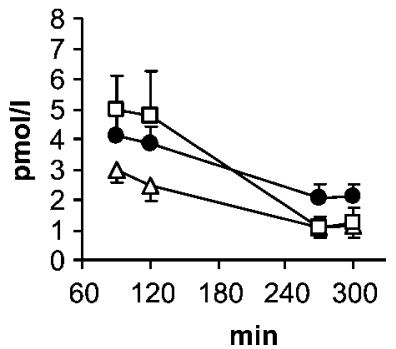

Figure 1 Plasma concentration of FFAs, glycerol, alanine, lactate and glucagon at basal steady-state period (90-120 min) and at clamp steady-state period (270-300 min) in LIPO, NONLIPO and NAÏVE. Significant differences between study groups are indicated at steady-state periods: ${ }^{*} P<0.05$ between LIPO and NAIIVE; $\S P<0.05$ between LIPO and NONLIPO; $P<0.05$ between NONLIPO and NAÏVE. LIPO $(\bullet)$, NONLIPO $(\triangle)$ and NAÏVE $(\square)$. 
chosen as a discriminative parameter for HIV-lipodystrophy, as fat loss in arms and legs and fat accumulation in the trunk region are a prerogative for the diagnosis of peripheral lipoatrophy and central fat accumulation consistent with lipodystrophy of the mixed type (2).

Rates of glucose appearance (Ra), rates of glucose disposal $(\mathrm{Rd})$ and rates of endogenous glucose production (EGP) were estimated during predefined steady-state periods (i.e. basal and clamp periods) at intervals of 10 min using Steele's non-steady-state equations as previously described (18). In the calculations of glucose turnover rates, the distribution volume of glucose was taken as $200 \mathrm{ml} / \mathrm{kg}$ BW, the pool fraction as 0.65 , plasma water was assumed to represent $93 \%$ of total plasma volume and total body water mass was set at $65 \%$ of BW (19). During the clamp, EGP was calculated as Ra minus rate of infusion of exogenous glucose (GIR). The glycolytic flux (GF) was estimated from the production rate of tritiated water $\left({ }^{3} \mathrm{H}_{2} \mathrm{O}\right)$ as previously described (20). The production rates of ${ }^{3} \mathrm{H}_{2} \mathrm{O}$ were linear in all study groups from 30 to $120 \mathrm{~min}$ and 210 to $300 \mathrm{~min}$ (all $r>0.98$ ). Exogenous glucose storage rate (EGS) was calculated as Rd minus GF, non-oxidative glucose metabolism (NOGM) as Rd minus glucose oxidation (GOX), and non-oxidative glucolysis as GF minus GOX (20). Insulin sensitivity index $\left(\mathrm{Si}_{\mathrm{Rd}}\right)$ was calculated as $\left(\left[\operatorname{Rd}_{\text {clamp }}-\operatorname{Rd}_{\text {basal }}\right] /[\mathrm{p}\right.$-insulin clamp p-insulin basal $/ \mathrm{p}$-glucose clamp $_{\text {- }}$ (19) and hepatic insulin sensitivity (HIS) as (1000/EGP basal $/ \mathrm{p}$-insulin basal $\left._{\text {bal }}\right)(21)$. The unit of SiRd is $\mu \mathrm{g}$ glucose/kg free fat mass (FFM) per min per $\mathrm{pmol} / \mathrm{l}$ insulin per $\mathrm{mmol} / \mathrm{l}$ glucose and the unit of HIS is $10^{3} / \mathrm{mg}$ glucose per kg FFM per min per $\mathrm{pmol} / \mathrm{l}$ insulin. Otherwise, throughout this paper the unit of glucose turnover rate is $\mathrm{mg} / \mathrm{kg}$ FFM per min.

First-phase insulin response to i.v. glucose bolus (Phi IVGTT $_{\text {) }}$ was calculated as the area under the curve (AUC) of plasma insulin 0-10 min after the i.v. glucose bolus divided by total AUC of plasma glucose $0-10 \mathrm{~min}$ after the i.v. glucose bolus as previously suggested (19). The unit of $\mathrm{Phi}_{\text {IVGTT }}$ is pmol insulin $/ \mathrm{mmol}$ glucose. First-phase insulin response was evaluated relatively to insulin sensitivity (22). The disposition index (Di) was defined as the product of $\mathrm{Si}_{\mathrm{Rd}}$ and Phi $\mathrm{I}_{\text {IVGTT }}$.

\section{Statistics}

Data are presented as means \pm S.E.M. and as medians and ranges when distributions were skewed. ANOVA was performed to compare the distribution of the glucose metabolic data of the three study groups. It appeared that RLF was a strong discriminator between HIVinfected patients with and without lipodystrophy; however, age was also different between groups. Accordingly, we calculated the impact of RLF adjusted for age on metabolic variables by univariate ANOVA, with patient groups (qualitative factors) and RLF and age (quantitative factors) as covariates. Given the significant impact of
RLF, Student's t-test was used to compare the distribution of metabolic data between cases and each group of control subjects. Pearson correlation coefficient (r) was applied for measurements of associations between variables for the total study group. Adjustment for age and percentage of total fat mass was performed calculating the partial correlation coefficient between variables. If data distribution was skewed, data were log transformed before applying ANOVA and $t$-tests and before calculation of a correlation coefficient. Calculations were performed by SPSS (SPSS version 12.0; SPSS Inc., Chicago, IL, USA). Two-sided $P$ values less than 0.05 were defined as statistically significant.

\section{Results}

\section{Characteristics of the study groups}

LIPO were older than NONLIPO and NAÏVE $(50 \pm 2$ years vs $43 \pm 2$ vs $36 \pm 3, P<0.01$ ), whereas no significant differences between groups in body mass index $\left(24.7 \pm 0.6 \mathrm{~kg} / \mathrm{m}^{2}\right.$ vs $22.5 \pm 0.8$ vs $24.8 \pm 1.0$, ANOVA, $P=$ not significant $(\mathrm{ns}))$ and total fat mass $(16 \pm 1 \mathrm{~kg}$ vs $13 \pm 2$ vs $20 \pm 2$, ANOVA, $P=$ ns) were observed. Both trunk fat mass given as absolute value (LIPO $9.8 \pm 1.0 \mathrm{~kg}$ vs NONLIPO $6.7 \pm 0.9$ vs NAÏVE $9.5 \pm 1.1$, ANOVA, $P=\mathrm{ns}$ ) and as trunk fat mass normalization by division with body weight $(11.9 \pm 0.9 \%$ vs $9.1 \pm 1.1$ vs $11.9 \pm 1.1$, ANOVA, $P=\mathrm{ns}$ ) did not differ significantly between study groups. In contrast, limb fat mass differed between groups both as absolute value (ANOVA, $P<0.02)$ and after normalization by body weight (ANOVA, $P<0.01$ ); thus, NAÏVE displayed increased limb fat $(8.6 \pm 0.8 \mathrm{~kg}, 10.8 \pm 0.8 \%)$ compared with LIPO $(5.6 \pm 0.6 \mathrm{~kg}, \quad P<0.01 ; 6.8 \pm 0.6 \%, P<0.01)$ and compared with NONLIPO $(5.4 \pm 0.6 \mathrm{~kg}, P<0.01$; $7.4 \pm 0.7 \%, P<0.01)$. RLF differed between groups (ANOVA, $P<0.001$ ), such that RLF was significantly reduced in LIPO $(58 \pm 4 \%)$ compared with NONLIPO $(89 \pm 7, P<0.001)$ and NAIIVE $(92 \pm 5, P<0.001)$, consistent with lipodystrophy in LIPO. Basal glucose concentration was similar in the groups (the means for individual groups ranged from 4.80 to $4.85 \mathrm{mmol} / \mathrm{l}$, $P=n s$ and all subjects had plasma glucose $\leq 6.1 \mathrm{mmol} / \mathrm{l})$.

Duration of HIV infection was: in LIPO, 99 \pm 14 months, NONLIPO, $72 \pm 11$ and NAÏVE, 61 \pm 25 , ANOVA, $P=$ ns. All LIPO and all NONLIPO were treated with nucleoside reverse transcriptase inhibitors (NRTIs) as part of HAART and mean duration of therapy for this class of drug was $47 \pm 7$ months and $42 \pm 6, P=$ ns. Frequently used NRTIs in LIPO and NONLIPO were Lamivudine (83\%), Zidovudine (50\%) and Stavudine $(47 \%)$ respectively. As part of the HAART, protease inhibitors (PIs) were used by $90 \%$ of LIPO and NONLIPO. Frequently used PIs were Indinavir (33\%), Ritonavir (31\%) and Nelfinavir (22\%). The components of HAART did not differ between LIPO and 
NONLIPO. CD4 cell numbers were similar between study groups (LIPO $427 \pm 45 \mathrm{cells} / \mu \mathrm{l}, \quad$ NONLIPO $352 \pm 46$ and NAÏVE $521 \pm 90$, ANOVA, $P=n s)$. LIPO and NONLIPO both displayed suppressed HIV-RNA (median $<20$ copies/ml). NAÏVE had a median HIV-RNA of 14900 copies/ml.

\section{Basal and insulin-stimulated glucose metabolism}

Basal and clamp insulin concentrations were increased in LIPO $(77 \pm 11 \mathrm{pmol} / \mathrm{l}$ and $535 \pm 35 \mathrm{pmol} / \mathrm{l})$ compared with NONLIPO ( $32 \pm 4$ and $392 \pm 16$, all $P<0.01$ ) and NAÏVE $(37 \pm 5$ and $445 \pm 26$, all $P<0.01)$. Table 1 presents glucose metabolic data including lipid oxidation. During the basal period no statistically significant differences were found between the groups. During the clamp significant reductions in Rd, NOGM and EGS were found in LIPO compared with NONLIPO and NAÏVE. HIS was also significantly reduced in LIPO compared with NONLIPO and NAÏVE (Table 2). $\mathrm{Si}_{\mathrm{Rd}}$, incremental Rd, NOGM and EGS were twofold greater in NONLIPO and NAÏVE compared with LIPO. Incremental GOX was increased in NONLIPO compared with LIPO and incremental lipid oxidation was increased in LIPO relative to NONLIPO.

\section{Basal and insulin-stimulated plasma concentrations of FFAs, glycerol, alanine, Iactate, glucagon, total cholesterol, HDL cholesterol and triglyceride}

Basal FFA concentrations were similar in the study groups (Fig. 1). However, clamp FFA was lower in NAIIVE compared with LIPO and NONLIPO separately, and lower in NONLIPO compared with LIPO (all $P<0.05)$. Basal glycerol concentration tended to be lower in NAÏVE compared with LIPO and NONLIPO separately (all $P<0.12$ ). Clamp glycerol concentration was lower in NAÏVE compared with LIPO $(P<0.01)$. Basal alanine concentration was lower in NAÏVE relatively to LIPO and clamp alanine was lower in NAÏVE and in NONLIPO compared with LIPO (all $P<0.03$ ). Basal lactate concentration was lower in NAÏVE

Table 1 Glucose metabolism including lipid oxidation as estimated by the combined use of glucose tracer infusion, indirect calorimetry and hyperinsulinaemic euglycaemic clamp technique.

\begin{tabular}{|c|c|c|c|c|c|c|c|c|}
\hline & \multicolumn{3}{|c|}{ Basal $^{*}$} & \multicolumn{3}{|c|}{ Clamp } & \multirow{2}{*}{$\begin{array}{l}\text { ANOVA clamp } \\
\text { (between } \\
\text { groups) }\end{array}$} & \multirow{2}{*}{$\begin{array}{l}\text { ANOVA clamp } \\
\text { (impact of } \\
\text { RLF)§ }\end{array}$} \\
\hline & LIPO & NONLIPO & NAÏVE & LIPO & NONLIPO & NAÏVE & & \\
\hline No. of subjects & 18 & 18 & 7 & 18 & 18 & 7 & & \\
\hline $\mathrm{Rd}$ & $2.7(0.1)$ & $2.7(0.2)$ & $2.7(0.1)$ & $5.9(0.5)^{\mathrm{ab}}$ & $8.9(0.6)$ & $8.9(0.3)$ & $<0.001$ & $<0.001$ \\
\hline GOX & $2.5(0.2)$ & $2.3(0.2)$ & $2.4(0.3)$ & $3.3(0.2)$ & $4.0(0.3)$ & $3.6(0.3)$ & ns & ns \\
\hline GF & $2.0(0.2)$ & $1.5(0.2)$ & $2.0(0.2)$ & $2.9(0.4)$ & $3.0(0.5)$ & $3.2(0.3)$ & ns & ns \\
\hline NOGM (GF-GOX) & $-0.5(0.3)$ & $-0.8(0.3)$ & $-0.5(0.4)$ & $-0.4(0.5)$ & $-1.0(0.5) \dagger$ & $-0.4(0.2)$ & ns & ns \\
\hline EGP (Ra-GIR) & $2.7(0.1)$ & $2.7(0.1)$ & $2.8(0.1)$ & $0.6(0.2)$ & $0.4(0.3)$ & $1.3(0.3)$ & ns & ns \\
\hline EGS (Rd-GF) & $0.8(0.2)$ & $1.2(0.3)$ & $0.8(0.2)$ & $3.0(0.6)^{\mathrm{cd}}$ & $5.9(0.8)$ & $5.7(0.5)$ & $<0.02$ & $<0.05$ \\
\hline NOGM (Rd-GOX) & $0.3(0.2)$ & $0.4(0.2)$ & $0.3(0.4)$ & $2.5(0.4)^{\mathrm{bc}}$ & $4.9(0.5)$ & $5.3(0.5)$ & $<0.001$ & $<0.004$ \\
\hline $\begin{array}{l}\text { Lipid oxidation } \\
\text { (LIPOX) }\end{array}$ & $0.94(0.08)$ & $0.99(0.11)$ & $0.79(0.18)$ & $0.57(0.07)$ & $0.36(0.09)$ & $0.24(0.11)$ & ns & ns \\
\hline
\end{tabular}

Mean (S.E.M.). Unit: mg/kg FFM per min; ns, not statistically significant.

${ }^{*}$ During the basal period all differences between study groups were statistically insignificant $(P>0.05$, ANOVA). a, $P<0.001$ for LIPO vs NONLIPO b, $P<0.001$ for LIPO vs NAïVE; c, $P<0.01$ for LIPO vs NONLIPO; $d, P<0.01$ for LIPO vs NAïVE; $\dagger$, value is different from zero $(P<0.05) ; \S$, adjusted for age. NOGM, non-oxidative glycolysis.

Table 2 Hepatic insulin sensitivity and incremental responses of glucose and lipid turnover rates after insulin stimulation.

\begin{tabular}{|c|c|c|c|c|c|}
\hline & LIPO & NONLIPO & NAÏVE & $\begin{array}{c}\text { ANOVA } \\
\text { (between groups) }\end{array}$ & $\begin{array}{c}\text { ANOVA } \\
\text { (impact of RLF)§ }\end{array}$ \\
\hline HIS & $7.2(1.1)^{\mathrm{cf}}$ & $16.1(2.2)$ & $11.8(1.6)$ & $<0.003$ & $<0.001$ \\
\hline \multicolumn{6}{|c|}{ Incremental turnover rates } \\
\hline $\mathrm{Si}_{\mathrm{Rd}}$ & $1.5(0.3)^{\mathrm{ab}}$ & $3.6(0.4)$ & $3.2(0.3)$ & $<0.0001$ & $<0.0001$ \\
\hline $\mathrm{Rd}$ & $3.1(0.4)^{\mathrm{ab}}$ & $6.3(0.6)$ & $6.2(0.4)$ & $<0.0001$ & $<0.0001$ \\
\hline GOX & $0.9(0.2)^{\mathrm{c}}$ & $1.7(0.2)$ & $1.2(0.4)$ & $<0.03$ & $<0.03$ \\
\hline GF & $0.9(0.4)$ & $1.5(0.5)$ & $1.3(0.3)$ & ns & ns \\
\hline EGP & $-2.1(0.2)$ & $-2.3(0.3)$ & $-1.5(0.3)$ & ns & ns \\
\hline EGS & $2.2(0.6)^{\mathrm{de}}$ & $4.6(0.8)$ & $5.0(0.5)$ & $<0.03$ & $<0.02$ \\
\hline NOGM & $2.3(0.4)^{c d}$ & $4.5(0.6)$ & $5.0(0.6)$ & $<0.004$ & $<0.003$ \\
\hline LIPOX & $-0.37(0.07)^{\mathrm{e}}$ & $-0.63(0.08)$ & $-0.55(0.09)$ & ns & $<0.03$ \\
\hline
\end{tabular}

Mean (S.E.M.). Unit: $\mathrm{mg} / \mathrm{kg}$ FFM per min except for $\mathrm{Si}_{\mathrm{Rd}}$ and HIS (see Patients and methods); §, adjusted for age.

${ }^{\mathrm{a}} P<0.001$ for LIPO vs NONLIPO; ${ }^{\mathrm{b}} P<0.001$ for LIPO vs NAÏVE; ${ }^{\mathrm{c}} P<0.01$ for LIPO vs NONLIPO; ${ }^{\mathrm{d}} P<0.01$ for LIPO vs NAÏVE; ${ }^{\mathrm{e}} P<0.05$ for LIPO vs NONLIPO; ${ }^{\dagger} P<0.05$ for LIPO vs NAÏVE. 
compared with LIPO and clamp lactate was lower in NAÏVE compared with NONLIPO and LIPO separately (all $P<0.01$ ). In LIPO, basal glucagon concentration tended to be higher than NONLIPO and clamp glucagon tended to be increased in LIPO compared with NONLIPO and NAÏVE separately (all $P<0.12$ ). Seven LIPO compared with 14 NONLIPO had undetectable low glucagon concentration during clamp $(P<0.05)$. Basal and clamp plasma total cholesterol was increased in LIPO (6.2 $\pm 0.4 \mathrm{mmol} / \mathrm{l}$ and 6.1 \pm 0.4$)$ compared with NONLIPO $(4.9 \pm 0.2$ and $4.7 \pm 0.2, P<0.01)$ and NAÏVE $(4.7 \pm 0.1$ and $4.5 \pm 0.1, P=0.01$, data not shown). Basal plasma HDL cholesterol was low but similar between groups (range 0.97-1.01 mmol/l, all $P>0.7$, data not shown). Basal log10 plasma triglyceride was insignificantly increased in LIPO $(0.47 \pm 0.08 \mathrm{mmol} / \mathrm{l})$ compared with NONLIPO

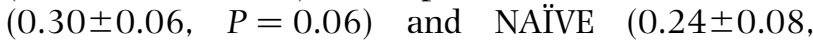
$P=0.06)$ and also clamp log10 plasma triglyceride was increased in LIPO $(0.44 \pm 0.08 \mathrm{mmol} / \mathrm{l})$ compared with NONLIPO $(0.24 \pm 0.07, P=0.07)$ and NAÏVE (0.17 $\pm 0.09, P<0.05$ data not shown).

\section{Association of fat distribution, HIS, glucose and lipid turnover rates}

In all patients, RLF (unadjusted and adjusted for age and total fat mass) correlated highly significantly and positively with HIS, the insulin-stimulated and incremental values of Rd, NOGM, EGS and incremental GOX, whereas RLF (unadjusted and adjusted for age and total fat mass) correlated inversely with insulin stimulated and incremental LIPOX (Table 3). The correlations of limb and trunk fat masses versus HIS and Rd in LIPO were insignificant, whereas correlations of HIS and $\mathrm{Rd}$ versus the ratio of limb to trunk fat mass appeared to be highly significant in LIPO (Table 4). In contrast, the combined group of NONLIPO and NAÏVE

Table 3 Association of RLF versus HIS and measures of insulinstimulated glucose and lipid turnover rates in combined study groups.

\begin{tabular}{|c|c|c|}
\hline & RLF & $\mathbf{R L F}$ (adjusted) $\dagger$ \\
\hline HIS & $0.71^{\star \star \star}$ & $0.69^{\star \star \star}$ \\
\hline ClampRd & $0.63^{\star \star \star}$ & $0.63^{\star \star \star}$ \\
\hline IncrRd & $0.70^{\star \star \star}$ & $0.71^{\star \star \star}$ \\
\hline ClampNOGM & $0.55^{\star \star \star}$ & $0.53^{\star \star \star}$ \\
\hline IncrNOGM & $0.54^{* * *}$ & $0.50^{\star *}$ \\
\hline ClampEGS & $0.45^{\star \star}$ & $0.36^{\star}$ \\
\hline IncrEGS & $0.48^{\star *}$ & $0.40^{* *}$ \\
\hline ClampGOX & $0.32^{\star}$ & 0.28 \\
\hline IncrGOX & $0.49^{\star \star}$ & $0.51^{\star \star}$ \\
\hline ClampLIPOX & $-0.40^{\star \star}$ & $-0.32^{\star}$ \\
\hline IncrLIPOX & $-0.50^{\star \star}$ & $-0.52^{\star \star \star}$ \\
\hline
\end{tabular}

Combined study groups, $n=43$; $\uparrow$, adjusted for total fat mass (\%) and age (years).

${ }^{\star \star \star} P<0.001,{ }^{\star \star} P<0.01,{ }^{\star} P<0.05$

Incr, incremental. exhibited significant inverse correlations of HIS and Rd versus limb and trunk fat masses (Table 4).

RLF was significantly and inversely correlated with plasma concentrations of triglyceride, FFA and glycerol during the clamp (Table 5). Insulin-stimulated $\mathrm{Rd}$ and NOGM were inversely correlated with clamp plasma concentrations of FFA and glycerol (Table 5).

In all subjects $(n=43)$, HIS correlated significantly with Rd, EGS, incremental GOX (Fig. 2), NOGM $(r=0.55, P<0.001$, data not shown) and incremental lipid oxidation $(r=-0.33, P<0.05$, data not shown). GOX and LIPOX correlated strongly and inversely during fasting (basal, $r=-0.77, P<0.001$ ) and during the clamp $(r=-0.68, P<0.001$, data not shown). In addition, EGS and NOGM were strongly correlated $(r=0.80, P<0.001$, data not shown). Basal glucagon concentration was significantly inversely correlated with HIS $(r=-0.46, P<0.01$, data not shown). This correlation was robust for adjustment for age, total fat mass and RLF $(P<0.05)$. Basal plasma concentration of glucagon was not significantly correlated with RLF $(r=(0.21, P=0.16$, data not shown).

\section{Di and $\beta$-cell function}

Di was reduced $46 \%$ in LIPO compared with the combined groups of NONLIPO and NAÏVE (median 35 (range 2-209) vs median 65 (range 15-143), Mann-Whitney test, $P=0.05$ ). The reduced $\mathrm{Di}$ in LIPO was due to an impaired $\mathrm{Si}_{\mathrm{Rd}}(1.5 \pm 0.3$ vs $3.5 \pm 0.3, P<0.0001$ age adjusted), which was not compensated by increased Phi IVGTT $_{\text {(median }} 22$ (range $8-237$ ) vs median 18 (range 6-51), $P=$ ns). Figure 3 shows the Phi $\mathrm{I}_{\text {IVGTT }}$ plotted against $\mathrm{Si}_{\mathrm{Rd}}$ for all subjects individually. Insulin resistance may arbitrary be defined as insulin sensitivity below the 25th percentile of the population studied (23). Therefore, we marked the 25th percentile of the $\mathrm{Si}_{\mathrm{Rd}}$ of the combined groups of NONLIPO and NAÏVE (the arrow on the $\mathrm{x}$ axis on Fig. 3). In parallel, we indicated the 25th percentile of the Di of the combined groups of NONLIPO and NAÏVE by the hyperbolic solid line in Fig. 3 proposing that a left shift relative to this line would suggest a low Di of the HIV-infected patient. In accordance, it appeared that an increased fraction of LIPO displayed a combination of low insulin sensitivity and low Di compared with the combined group of NONLIPO and NAÏVE ( $50 \%$ vs $12 \%$, Chi-square test, $P<0.01)$.

\section{Discussion}

Our data have indicated that normoglycaemic lipodystrophic HIV-infected patients on HAART (LIPO) may display hepatic and peripheral insulin resistance including impaired EGS, GOX and increased LIPOX compared with normoglycaemic non-lipodystrophic 
Table 4 Association of limb fat and trunk fat versus HIS and clamp and incremental glucose turnover rates in all patients, in LIPO and in the combined groups of NONLIPO and NAÏVE.

\begin{tabular}{|c|c|c|c|c|c|c|c|c|c|}
\hline & \multicolumn{3}{|c|}{ All patients $(n=43)$} & \multicolumn{3}{|c|}{ LIPO $(n=18)$} & \multicolumn{3}{|c|}{ NONLIPO+ NAÏVE $(n=25)$} \\
\hline & HIS & ClampRd & IncrRd & HIS & ClampRd & IncrRd & HIS & ClampRd & IncrRd \\
\hline $\begin{array}{l}\text { Limb fat }(\%) \\
\text { Limb fat }(k g)\end{array}$ & $\begin{array}{l}-0.13 \\
-0.21\end{array}$ & $\begin{array}{r}0.10 \\
-0.01\end{array}$ & $\begin{array}{l}0.12 \\
0.02\end{array}$ & $\begin{array}{l}0.26 \\
0.22\end{array}$ & $\begin{array}{l}0.24 \\
0.10\end{array}$ & $\begin{array}{l}0.23 \\
0.12\end{array}$ & $\begin{array}{l}-0.46^{\star} \\
-0.49^{\star}\end{array}$ & $\begin{array}{l}-0.25 \\
-0.23\end{array}$ & $\begin{array}{l}-0.19 \\
-0.17\end{array}$ \\
\hline $\begin{array}{l}\text { Trunk fat }(\%) \\
\text { Trunk fat }(\mathrm{kg})\end{array}$ & $\begin{array}{l}-0.57^{\star \star *} \\
-0.52^{\star \star *}\end{array}$ & $\begin{array}{l}-0.46^{\star *} \\
-0.45^{\star *}\end{array}$ & $\begin{array}{l}-0.49^{\star *} \\
-0.46^{\star *}\end{array}$ & $\begin{array}{l}-0.19 \\
-0.14\end{array}$ & $\begin{array}{l}-0.22 \\
-0.27\end{array}$ & $\begin{array}{l}-0.26 \\
-0.27\end{array}$ & $\begin{array}{l}-0.65^{\star \star *} \\
-0.62^{\star *}\end{array}$ & $\begin{array}{l}-0.49^{\star} \\
-0.44^{*}\end{array}$ & $\begin{array}{l}-0.53^{\star *} \\
-0.46^{*}\end{array}$ \\
\hline RLF (\%) & $0.71^{\star \star \star}$ & $0.63^{\star \star \star}$ & $0.70^{\star \star \star}$ & $0.62^{\star \star}$ & $0.61^{\star \star}$ & $0.63^{\star \star}$ & $0.61^{\star \star}$ & 0.36 & $0.50^{*}$ \\
\hline
\end{tabular}

${ }^{\star * \star} P<0.001,{ }^{* *} P<0.01,{ }^{*} P<0.05$

Table 5 Associations between RLF, Rd and NOGM versus clamp plasma triglyceride, FFAs and glycerol in the combined study groups.

\begin{tabular}{llll}
\hline & RLF & ClampRd & ClampNOGM \\
\hline Clamp log10 triglyceride & $-0.42^{\star \star}$ & -0.25 & -0.16 \\
Clamp FFAs & $-0.55^{\star \star \star}$ & $-0.53^{\star \star}$ & $-0.43^{\star \star}$ \\
Clamp glycerol & $-0.48^{\star \star}$ & $-0.37^{\star}$ & $-0.33^{\star}$ \\
\hline
\end{tabular}

Combined study groups, $n=43 ;{ }^{\star \star \star} P<0.001,{ }^{\star \star} P<0.01,{ }^{\star} P<0.05$

HIV-infected patients on HAART (NONLIPO) and HIVinfected patients naïve to HAART (NAÏVE). Such glucose metabolic aberrations appeared to be strongly associated with the lipodystrophic fat distribution independently of the age and total fat mass of the subjects. In addition, we have provided evidence suggesting that LIPO exhibit defects in first-phase insulin secretion following an intravenous glucose bolus.

The protease inhibitors, which are one of the cornerstones in HAART, have been shown to acutely inhibit glucose transporter-4 (GLUT-4) in cell cultures (24), and to decrease insulin sensitivity in vivo $(25,26)$ making it difficult to distinguish between the effect of HAART and the effect of fat redistribution on metabolic aberrations in HIV-infected patients. The protease inhibitor-induced insulin resistance appears, however, to be reversible within a few hours following discontinuation of the drug (26). In the present study, components of HAART were balanced between study groups on antiretroviral therapy and patients were studied after at least $16 \mathrm{~h}$ discontinuation of antiretroviral drugs to ensure that the acute effects of HAART on substrate metabolism would be small.

\section{Substrate metabolism}

The normoglycaemic LIPO exhibited severe impairments in insulin-stimulated EGS and in NOGM. In HIV-negative individuals, EGS has been shown to be an index of glycogen storage (27). In the present study of normoglycaemic HIV-infected patients, the two surrogate parameters of glycogen deposition, i.e. EGS and NOGM, correlated strongly ( $r^{2}=0.65$ in all patients). Accordingly, a major defect in glucose metabolism in LIPO appears to be impaired insulin-stimulated glycogen synthesis. Defects of similar magnitude in this glucose metabolic pathway have been described in HIV-negative subjects with overt type 2 diabetes mellitus (28).

We observed that the normoglycaemic LIPO displayed decreased insulin-stimulated GOX and an attenuated insulin-stimulated suppression of LIPOX at similar levels as has been reported for HIV-negative individuals with insulin resistance and type 2 diabetes mellitus $(29,30)$. The strong associations between basal and insulin-stimulated LIPOX and GOX suggest
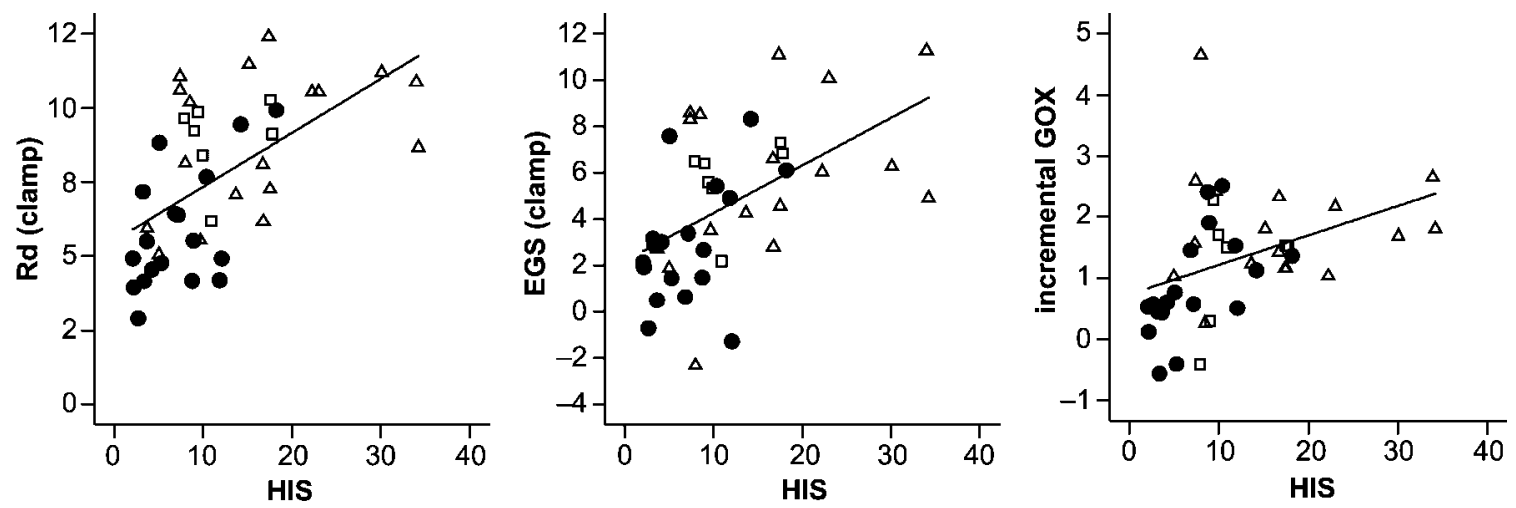

Figure 2 Scatter plots showing the correlations between HIS versus insulin-stimulated Rd clamp $(r=0.57, P<0.001)$, EGS clamp $(r=0.51, P<0.001)$ and incremental GOX $(r=0.39, P<0.01)$. The unit of HIS is $10^{3} / \mathrm{mg}$ glucose per kg FFM per min per pmol/l insulin. The unit of Rd, EGS and GOX is $\mathrm{mg} / \mathrm{kg}$ FFM per min. LIPO $(\bullet)$, NONLIPO $(\triangle)$ and NAÏVE $(\square)$. 


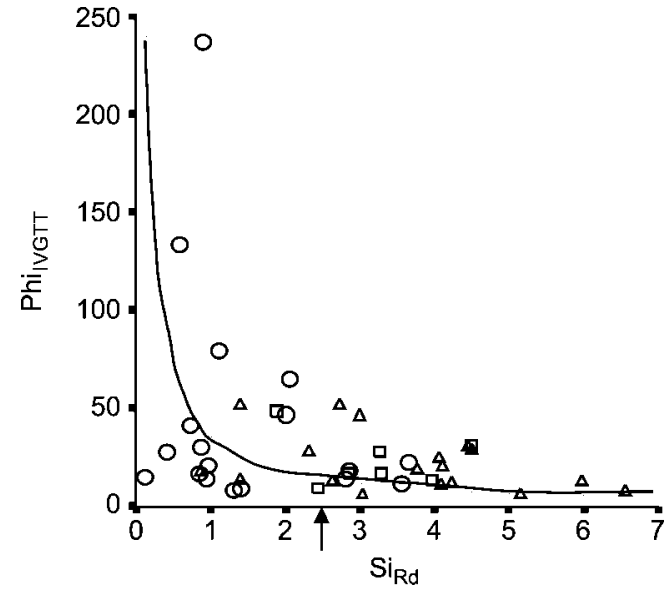

Figure 3 Plot of Phi $\mathrm{I}_{\mathrm{VG}}$ against $\mathrm{Si}_{\mathrm{Rd}}$. The arrow on the $\mathrm{x}$ axis indicates the 25th percentile of $\mathrm{Si}_{\mathrm{Rd}}$ for the combined groups of NONLIPO and NAÏVE. The hyperbolic solid line indicates the 25th percentile of the Di of the combined groups of NAIIVE and NONLIPO. The unit of $\mathrm{Si}_{\mathrm{Rd}}$ is $\mu \mathrm{g}$ glucose/kg FFM per min per $\mathrm{pmol} / \mathrm{l}$ insulin per $\mathrm{mmol} / \mathrm{l}$ glucose. The unit of Phi $\mathrm{IVGTT}_{\text {iv }} \mathrm{pmol}$ insulin/mmol glucose. LIPO (O), NONLIPO $(\triangle)$ and NAïVE ( $\square$ ).

an important link between muscle glucose metabolism and lipid metabolism in HIV-infected patients (28).

Indirect calorimetry provides estimates of the oxidation of glucose from glycogen stores, which do not appear in the tracer calculations. On the other hand, indirect calorimetry does not provide an estimate of the glucose that has been directed to non-oxidative glycolysis (lactate and alanine production), which appears in the tracer calculations of GF $(20,27)$. LIPO and NAÏVE appeared to display similar levels of GF and GOX during the insulin-stimulated steady-state period. However, this may not reflect similar non-oxidative glycolysis and endogenous glucose fluxes as we showed that the clamp plasma alanine and lactate concentrations were significantly increased in LIPO compared with NAÏVE, which supports a relatively increased non-oxidative glycolysis in LIPO (31). The observation in NONLIPO that GF was reduced compared with GOX may represent a relatively low non-oxidative glycolysis, which is supported by the finding of a relatively low plasma alanine concentration during clamp in NONLIPO.

Our finding of reduced insulin-stimulated EGS/ NOGM and GOX in LIPO is consistent with the results from Behrens and co-workers (32) on reduced insulin-stimulated NOGM and GOX in six lipodystrophic HIV-infected patients on HAART compared with six HIV-infected patients, who had never received antiretroviral therapy. Similar defects in glucose metabolism were observed in six lipodystrophic HIV-infected patients on HAART compared with six healthy HIVnegative control subjects (33).

The mechanisms behind hepatic insulin resistance in LIPO compared with NONLIPO and NAÏVE were not addressed in our study. An increased accumulation of triglyceride in the liver of lipodystrophic HIV-infected patients has been observed (9). Increased liver fat is associated with hepatic and peripheral insulin resistance $(34,35)$. In addition, hepatic and peripheral insulin resistance seem to correlate (36), which was also observed in the present study. Another mechanism explaining, in part, the hepatic insulin resistance in LIPO might be a stimulatory effect of glucagon on the hepatic glucose production (37), which corresponds to our present finding of an inverse correlation between plasma glucagon concentration and HIS.

The hepatic glucose production during the insulin clamp ( $40 \mathrm{mU} / \mathrm{m}^{2}$ per $\left.\mathrm{min}\right)$ was almost fully suppressed in all study groups, which should be expected as it has been shown that HIV-negative individuals, who displayed a broad range of insulin sensitivity including mild type 2 diabetes, suppress hepatic glucose production by more than $75 \%$ in this setting $(18,38)$. Future studies should address whether lower insulin infusion rates, e.g. 10 or $20 \mathrm{mU} / \mathrm{m}^{-2}$ per min, may reveal defects in hepatic glucose production in HIV-lipodystrophy $(18,38)$.

Compared with LIPO and NONLIPO, NAÏVE displayed a lower basal and clamp glycerol concentration. If plasma glycerol concentration is accepted as an index of lipolysis at these predefined steady-state periods, our findings suggest a lower level of lipolysis in NAÏVE during both basal and insulin-stimulated conditions compared with the HIV-infected patients on HAART (i.e. LIPO and NONLIPO), which is consistent with former reports of increased rates of lipolysis in such patients $(8,39)$. Our data are also consistent with an increased rate of lipolysis in LIPO compared with NONLIPO, as the FFA concentration was increased during clamp and the insulin-mediated suppression of lipid oxidation was attenuated in LIPO. Increased rates of lipolysis are thought to be a causative factor of impaired Rd rate (40) and glycogen storage (41). Consistently, in the present study, concentrations of FFAs and glycerol during the clamp were inversely correlated with insulin-stimulated Rd and NOGM.

An interesting and as yet unresolved question regarding the pathophysiology of lipodystrophy in HIVinfected patients is whether metabolic adverse events are mainly related to peripheral subcutaneous lipoatrophy, truncal (visceral) lipohypertrophy, or both. The data from the present study may support the posibility that the fat redistribution as such, i.e. peripheral fat loss concomitant with central fat gain in lipodystrophic HIV-infected patients (who complain and display signs of this 'mixed condition') relates to glucose metabolic complications. This was suggested in LIPO by the missed significant correlations for glucose metabolism versus limb fat mass and trunk fat mass separately but, in the combined form, as a ratio, fat distribution correlated highly significantly with many measures of glucose and lipid metabolism (Tables 3 and 4). However, the present study was cross-sectional and to prove that 
the combined fat redistribution, as such, and not lipoatrophy or lipohypertrophy separately, is the strongest factor related to metabolic adverse events, a prospective setting is needed.

\section{Di and $\beta$-cell function}

LIPO displayed nearly 50\% reduction in Di compared with non-lipodystrophic HIV-infected patients suggesting $\beta$-cell dysfunction; however, the first-phase insulin secretion did not differ between LIPO and the combined group of NONLIPO and NAÏVE. Therefore, the insulin response may be normal in absolute terms but reduced for the degree of insulin resistance reflected by a lower Di $(22,42)$. Also, our data suggested that a greater proportion of LIPO might display a combination of low Di and low insulin sensitivity compared with NONLIPO and NAÏVE (Fig. 3). In a situation with an augmented demand for insulin, i.e. insulin resistance, insulin secretion may exceed the rate of synthesis, which leads to depletion of the insulin stores (43). This may affect, especially, the first-phase insulin response during an i.v. glucose load, despite a normal fasting glucose level (44). The insulin response to i.v. glucose is a very sensitive index of $\beta$-cell function compared with the insulin response to non-glucose secretagogues (45). The aetiology of the islet $\beta$-cell dysfunction in HIV-lipodystrophy is not known, but a hypothesis focusing on a deleterious effect of HAART on $\beta$-cell function has been discussed $(7,46)$. A defect in the incretin signalling may also explain the $\beta$-cell dysfunction (47). Alternatively, increased levels of FFAs have been shown to induce defects in $\beta$-cell function (48).

\section{Limitations}

The Botnia clamp (i.e. the combination of an IVGTT and a hyperinsulinaemic euglycaemic clamp), which was used in the present investigation, remains to be validated for the determination of various pathways of glucose metabolism by radioactive labelled glucose. However, it has recently been shown that the glucose disposal rates, whether using the Botnia combination or a traditional euglycaemic clamp, are highly correlated $(r>0.95)$ and comparable (mean difference $7 \%)(49)$.

In conclusion, we have provided evidence suggesting that normoglycaemic HIV-infected men with lipodystrophy may display impairments in multiple pathways of glucose and lipid metabolism involving muscle tissue, liver and pancreatic $\beta$-cells compared with normoglycaemic HIV-infected men without fat redistribution.

\section{Acknowledgements}

We thank Susanne Reimer, Lena Hansen and Anne Louise Sørensen for excellent technical assistance. This paper was supported financially in part by The Danish AIDS Foundation, The Novo Nordisk Foundation, The Copenhagen Hospital Cooperation Foundation, and the Danish Medical Research Council Foundation.

\section{References}

1 Chen D, Misra A \& Garg A. Clinical review 153: Lipodystrophy in human immunodeficiency virus-infected patients. Journal of Clinical Endocrinology and Metabolism 200287 4845-4856.

2 Carr A, Emery S, Law M, Puls R, Lundgren JD \& Powderly WG. An objective case definition of lipodystrophy in HIV-infected adults: a case-control study. Lancet $2003 \mathbf{3 6 1} 726-735$.

3 Kosmiski LA, Kuritzkes DR, Lichtenstein KA, Glueck DH, Gourley PJ, Stamm ER, Scherzinger AL \& Eckel RH. Fat distribution and metabolic changes are strongly correlated and energy expenditure is increased in the HIV lipodystrophy syndrome. AIDS 200115 1993-2000.

4 Mynarcik DC, McNurlan MA, Steigbigel RT, Fuhrer J \& Gelato MC. Association of severe insulin resistance with both loss of limb fat and elevated serum tumor necrosis factor receptor levels in HIV lipodystrophy. Journal of Acquired Immune Deficiency Syndrome 200025 312-321.

5 Carr A, Samaras K, Thorisdottir A, Kaufmann GR, Chisholm DJ \& Cooper DA. Diagnosis, prediction, and natural course of HIV-1 protease-inhibitor-associated lipodystrophy, hyperlipidaemia, and diabetes mellitus: a cohort study. Lancet 1999353 2093-2099.

6 Hadigan C, Meigs JB, Corcoran C, Rietschel P, Piecuch S, Basgoz N, Davis B, Sax P, Stanley T, Wilson PW, D’Agostino RB \& Grinspoon $\mathrm{S}$. Metabolic abnormalities and cardiovascular disease risk factors in adults with human immunodeficiency virus infection and lipodystrophy. Clinical Infectious Diseases 200132 130-139.

7 Woerle HJ, Mariuz PR, Meyer C, Reichman RC, Popa EM, Dostou JM, Welle SL \& Gerich JE. Mechanisms for the deterioration in glucose tolerance associated with HIV protease inhibitor regimens. Diabetes 200352 918-925.

8 Hadigan C, Borgonha S, Rabe J, Young V \& Grinspoon S. Increased rates of lipolysis among human immunodeficiency virus-infected men receiving highly active antiretroviral therapy. Metabolism 200251 1143-1147.

9 Sutinen J, Hakkinen AM, Westerbacka J, Seppala-Lindroos A, Vehkavaara S, Halavaara J, Jarvinen A, Ristola M \& Yki-Jarvinen $\mathrm{H}$. Increased fat accumulation in the liver in HIV-infected patients with antiretroviral therapy-associated lipodystrophy. AIDS 2002 $162183-2193$.

10 Gan SK, Samaras K, Thompson CH, Kraegen EW, Carr A Cooper DA \& Chisholm DJ. Altered myocellular and abdominal fat partitioning predict disturbance in insulin action in HIV protease inhibitor-related lipodystrophy. Diabetes 200251 $3163-3169$

11 Luzi L, Perseghin G, Tambussi G, Meneghini E, Scifo P, Pagliato E, Del Maschio A, Testolin G \& Lazzarin A. Intramyocellular lipid accumulation and reduced whole body lipid oxidation in HIV lipodystrophy. American Journal of Physiology, Endocrinology and Metabolism 2003284 E274-E280.

12 Lihn AS, Richelsen B, Pedersen SB, Haugaard SB, Rathje GS, Madsbad S \& Andersen O. Increased expression of TNF- $\alpha$, IL- 6 , and IL-8 in HALS: implications for reduced adiponectin expression and plasma levels. American Journal of Physiology, Endocrinology and Metabolism 2003285 E1072-E1080.

13 Carr A, Samaras K, Burton S, Law M, Freund J, Chisholm DJ \& Cooper DA. A syndrome of peripheral lipodystrophy, hyperlipidaemia and insulin resistance in patients receiving HIV protease inhibitors. AIDS 199812 F51-F58.

14 Andersen O, Haugaard SB, Andersen UB, Friis-Moller N, Storgaard H, Volund A, Nielsen JO, Iversen J \& Madsbad S. Lipodystrophy in human immunodeficiency virus patients impairs insulin action and induces defects in beta-cell function. Metabolism 200352 1343-1353. 
15 Frayn KN. Calculation of substrate oxidation rates in vivo from gaseous exchange. Journal of Applied Physiology 198355 628-634.

16 Fogh-Andersen N \& D’Orazio P. Proposal for standardizing directreading biosensors for blood glucose. Clinical Chemistry $1998 \mathbf{4 4}$ 655-659.

17 Holst JJ. Molecular heterogeneity of glucagon in normal subjects and in patients with glucagon-producing tumours. Diabetologia $198324359-365$.

18 Hother-Nielsen O, Henriksen JE, Holst JJ \& Beck-Nielsen H. Effects of insulin on glucose turnover rates in vivo: isotope dilution versus constant specific activity technique. Metabolism $1996 \mathbf{4 5}$ $82-91$.

19 Jensen CB, Storgaard H, Dela F, Holst JJ, Madsbad S \& Vaag AA. Early differential defects of insulin secretion and action in 19-year-old Caucasian men who had low birth weight. Diabetes $2002511271-1280$.

20 Del Prato S, Bonadonna RC, Bonora E, Gulli G, Solini A, Shank M \& DeFronzo RA. Characterization of cellular defects of insulin action in type 2 (non-insulin-dependent) diabetes mellitus. Journal of Clinical Investigation $199391484-494$.

21 Matsuda M \& DeFronzo RA. Insulin sensitivity indices obtained from oral glucose tolerance testing: comparison with the euglycemic insulin clamp. Diabetes Care 199922 1462-1470.

22 Kahn SE, Prigeon RL, McCulloch DK, Boyko EJ, Bergman RN, Schwartz MW, Neifing JL, Ward WK, Beard JC \& Palmer JP. Quantification of the relationship between insulin sensitivity and beta-cell function in human subjects. Evidence for a hyperbolic function. Diabetes $1993 \mathbf{4 2} 1663-1672$.

23 Beck-Nielsen H. General characteristics of the insulin resistance syndrome: prevalence and heritability. European Group for the study of Insulin Resistance (EGIR). Drugs 199958 (Suppl 1) 7-10.

24 Murata H, Hruz PW \& Mueckler M. The mechanism of insulin resistance caused by HIV protease inhibitor therapy. Journal of Biological Chemistry 2000275 20251-20254.

25 Noor MA, Seneviratne T, Aweeka FT, Lo JC, Schwarz JM, Mulligan K, Schambelan M \& Grunfeld C. Indinavir acutely inhibits insulin-stimulated glucose disposal in humans: a randomized, placebo-controlled study. AIDS 200216 F1-F8.

26 Hruz PW, Murata H, Qiu H \& Mueckler M. Indinavir induces acute and reversible peripheral insulin resistance in rats. Diabetes $200251937-942$.

27 Rossetti L, Lee YT, Ruiz J, Aldridge SC, Shamoon H \& Boden G. Quantitation of glycolysis and skeletal muscle glycogen synthesis in humans. American Journal of Physiology 1993265 E761-E769.

28 Vaag A, Alford F, Henriksen FL, Christopher M \& Beck-Nielsen H. Multiple defects of both hepatic and peripheral intracellular glucose processing contribute to the hyperglycaemia of NIDDM. Diabetologia 199538 326-336.

29 Blaak EE, Aggel-Leijssen DP, Wagenmakers AJ, Saris WH \& Van Baak MA. Impaired oxidation of plasma-derived fatty acids in type 2 diabetic subjects during moderate-intensity exercise. Diabetes $2000492102-2107$.

30 Kelley DE \& Mandarino LJ. Fuel selection in human skeletal muscle in insulin resistance: a reexamination. Diabetes $2000 \mathbf{4 9}$ 677-683.

31 Yki-Jarvinen H, Puhakainen I \& Koivisto VA. Effect of free fatty acids on glucose uptake and nonoxidative glycolysis across human forearm tissues in the basal state and during insulin stimulation. Journal of Clinical Endocrinology and Metabolism $1991721268-1277$.

32 Behrens GM, Boerner AR, Weber K, Van den Hoff J, Ockenga J, Brabant G \& Schmidt RE. Impaired glucose phosphorylation and transport in skeletal muscle cause insulin resistance in HIV-1-infected patients with lipodystrophy. Journal of Clinical Investigation 200232 1319-1327.

33 van der Valk M, Bisschop PH, Romijn JA, Ackermans MT, Lange JM, Endert E, Reiss P \& Sauerwein HP. Lipodystrophy in HIV-1-positive patients is associated with insulin resistance in multiple metabolic pathways. AIDS 200115 2093-2100.
34 Ryysy L, Hakkinen AM, Goto T, Vehkavaara S, Westerbacka J, Halavaara J \& Yki-Jarvinen H. Hepatic fat content and insulin action on free fatty acids and glucose metabolism rather than insulin absorption are associated with insulin requirements during insulin therapy in type 2 diabetic patients. Diabetes 2000 $49749-758$.

35 Seppala-Lindroos A, Vehkavaara S, Hakkinen AM, Goto T, Westerbacka J, Sovijarvi A, Halavaara J \& Yki-Jarvinen H. Fat accumulation in the liver is associated with defects in insulin suppression of glucose production and serum free fatty acids independent of obesity in normal men. Journal of Clinical Endocrinology and Metabolism 200287 3023-3028.

36 Miyazaki Y, Glass L, Triplitt C, Wajcberg E, Mandarino LJ \& DeFronzo RA. Abdominal fat distribution and peripheral and hepatic insulin resistance in type 2 diabetes mellitus. American Journal of Physiology, Endocrinology and Metabolism 2002283 E1135-E1143.

37 Shah P, Basu A, Basu R \& Rizza R. Impact of lack of suppression of glucagon on glucose tolerance in humans. American Journal of Physiology 1999277 E283-E290.

38 Staehr P, Hother-Nielsen O, Levin K, Holst JJ \& Beck-Nielsen H. Assessment of hepatic insulin action in obese type 2 diabetic patients. Diabetes $2001501363-1370$.

39 Hadigan C, Rabe J, Meininger G, Aliabadi N, Breu J \& Grinspoon S. Inhibition of lipolysis improves insulin sensitivity in protease inhibitor-treated HIV-infected men with fat redistribution. American Journal of Clinical Nutrition 2003 77 490-494.

40 Abbasi F, McLaughlin T, Lamendola C \& Reaven GM. Insulin regulation of plasma free fatty acid concentrations is abnormal in healthy subjects with muscle insulin resistance. Metabolism $200049151-154$.

41 Boden G, Chen X, Ruiz J, White JV \& Rossetti L. Mechanisms of fatty acid-induced inhibition of glucose uptake. Journal of Clinical Investigation $1994932438-2446$.

42 Bergman RN, Finegood DT \& Kahn SE. The evolution of beta-cell dysfunction and insulin resistance in type 2 diabetes. European Journal of Clinical Investigation 200232 (Suppl 3) 35-45.

43 Orland MJ \& Permutt MA. Comparative modulations of insulin secretion, pancreatic insulin content, and proinsulin mRNA in rats. Effects of $50 \%$ pancreatectomy and dexamethasone administration. Diabetes $1991 \mathbf{4 0} 181-189$.

44 Christiansen E, Tibell A, Rasmussen K, Tyden G \& Madsbad S. Defects in quantitative and qualitative beta-cell function following successful segmental pancreas transplantation. Danish-Swedish Study Group of Metabolic Effect of Pancreas Transplantation (DSSGMEPT). Transplantation Proceedings 199325 1186-1189.

45 Porte D Jr. Banting lecture 1990. Beta-cells in type II diabetes mellitus. Diabetes $1991 \mathbf{4 0} 166-180$.

46 Behrens G, Dejam A, Schmidt H, Balks HJ, Brabant G, Korner T, Stoll M \& Schmidt RE. Impaired glucose tolerance, beta cell function and lipid metabolism in HIV patients under treatment with protease inhibitors. AIDS 199913 F63-F70.

47 Edwards CM, Todd JF, Mahmoudi M, Wang Z, Wang RM, Ghatei MA \& Bloom SR. Glucagon-like peptide 1 has a physiological role in the control of postprandial glucose in humans: studies with the antagonist exendin 9-39. Diabetes 199948 86-93.

48 Kashyap S, Belfort R, Gastaldelli A, Pratipanawatr T, Berria R, Pratipanawatr W, Bajaj M, Mandarino L, DeFronzo R \& Cusi K. A sustained increase in plasma free fatty acids impairs insulin secretion in nondiabetic subjects genetically predisposed to develop type 2 diabetes. Diabetes 200352 2461-2474.

49 Tripathy D, Wessman Y, Gullstrom M, Tuomi T \& Groop L. Importance of obtaining independent measures of insulin secretion and insulin sensitivity during the same test: results with the Botnia clamp. Diabetes Care 200326 1395-1401.

Received 10 May 2004

Accepted 21 October 2004 